\section{Microscopy Coming Events}

\section{6}

Microscopy \& Microanalysis 2016

July 24-28, 2016

Columbus, $\mathrm{OH}$

www.microscopy.org

65th Annual Conference on Applications of X-ray Analysis: Denver X-ray

Conference

August, 1-5, 2016

Rosemont, IL

www.dxcicdd.com

International Conference on

Nanostructured Materials

August 7-12, 2016

Quebec, Canada

www.nano2016.org

XRM2016 - X-Ray Microscopy

August 15-19, 2016

Oxford, UK

www.xrm2016.com

EMC 2016: 16th European Microscopy

\section{Congress}

August 28-September 2, 2016

Lyon, France

http://emc2016.fr

National Society for Histotechnology: 42nd Annual Symposium/Convention September 16-21, 2016

Long Beach, CA

www.nsh.org

American Vacuum Society

November 6-11, 2016

Nashville, TN

www.avs.org

\section{Neuroscience 2016}

November 12-16, 2016

San Diego, CA

www.sfn.org

2017

Microscopy \& Microanalysis 2017

July 23-27, 2017

St. Louis, MO

www.microscopy.org

\section{8}

Microscopy \& Microanalysis 2018

August 5-9, 2018

Baltimore, MD

www.microscopy.org

\section{9}

Microscopy \& Microanalysis 2019

August 4-8, 2019

Portland, OR

www.microscopy.org

\section{0}

Microscopy \& Microanalysis 2020 August 2-6, 2020

Milwaukee, WI

www.microscopy.org

More Meetings and Courses

Check the complete calendar near the back of this magazine.

\title{
Microscopy Reveals How the Hydra Opens its Mouth
}

\author{
Stephen W. Carmichael \\ Mayo Clinic, Rochester, MN 55905 \\ carmichael.stephen@mayo.edu
}

The hydra is a simple freshwater animal famous for its regenerative capabilities, reminiscent of its mythological namesake, the multi-headed Hydra. The hydra has a morphologically simple body plan with a radially symmetric tubular body column topped with a dome-shaped hypostome. The hypostome is surrounded by a ring of tentacles. The animal has two layers of epithelium, an outer ectoderm, and a thicker inner endoderm. Between them is a layer of extracellular matrix called the mesoglea. In the center of the hypostome is the mouth of the hydra, characterized by a distinct group of cells, but there is no permanent mouth opening. For the animal to feed, the hydra must tear a hole through the epithelial tissue of its hypostome each time it opens its mouth. Two mechanisms for this event have been proposed. One involves cellular rearrangement and the other is elastic deformation of cells. Until now the tools have not been available to definitively determine which of these two mechanisms is involved in feeding. In a recent study, Jason Carter,

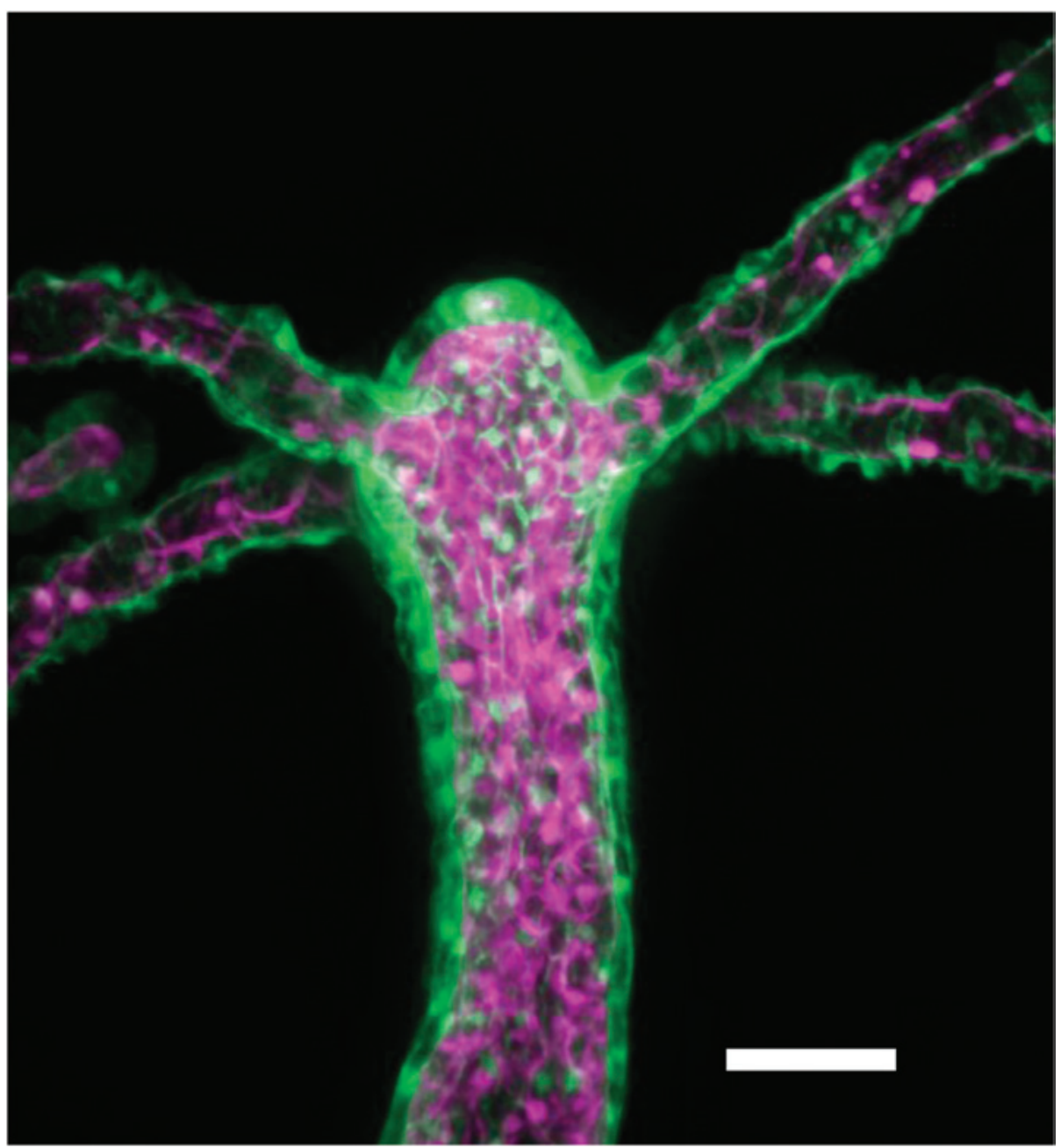

Figure 1: Representative image of an adult transgenic hydra expressing GFP in the ectoderm and DsRed2 in the endoderm. Scale bar $=200 \mu \mathrm{m}$. Image credit: Callen Hyland. 
Callen Hyland, Robert Steele, and Eva-Maria Collins [1] employed live imaging of hypostomes in transgenic hydra expressing fluorescent proteins in the two epithelial layers and quantitative image analysis to investigate the dynamics of mouth opening in hydra, apparently for the first time.

Ectodermal cells were labeled with green fluorescent protein (GFP), and endodermal cells were labeled with DsRed2, and both were detected using epifluorescence microscopy (see Figure 1). Carter et al. found that the dynamics of mouth opening occurred over a period of about 30 seconds to one minute. This is the same timescale as contraction bursts of the hydra body generated by epitheliomuscular processes in structures called myonemes that control the shape of the water-filled body. In the body column the myonemes in the ectoderm are arranged longitudinally, whereas those in the endoderm are arranged circularly. It is known that body contractions are initiated by a neural net (which represents a primitive nervous system) that controls myoneme contractions.

In the hypostome, ectodermal myonemes are arranged radially and endodermal myonemes are arranged circularly, suggesting that ectodermal myoneme contractions may be responsible for mouth opening, and endodermal myoneme contractions may control closing of the mouth. To test this hypothesis the authors used magnesium chloride as a muscle relaxant and confirmed experimentally that hydra mouth opening requires activity of the radially arranged ectodermal myonemes. By tracking individual cells during spontaneous mouth openings, they showed that cells maintain existing contacts and do not undergo rearrangement. Cell shape analysis further confirmed that mouth expansion occurs exclusively through viscoelastic deformation of cells. Specifically cells were compressed perpendicularly to the mouth boundary and elongated parallel to it. Further experiments showed that changes in cell shape correlated perfectly with mouth-opening changes.

It was astounding that the mouth could expand to sometimes be wider than the body column during feeding, allowing the animal to engulf prey larger than itself. Because one animal can open its mouth consecutively to different sizes, Carter et al. suggested that the degree of mouth opening is controlled through neuronal signaling.

Carter et al. proposed future experiments on the molecular mechanisms of myoneme control through the nervous system; visualization of myoneme contractions in real time will allow the development of a physical model for the entire mouth opening process. From a more general standpoint this study demonstrated the structural simplicity and availability of in-vivo labeling techniques that make hydra an excellent model for studying fundamental biomechanical processes on both the cellular and tissue levels [2].

\section{References}

[1] JA Carter et al., Biophys J 110 (2016) 1191-1201.

[2] The author gratefully acknowledges Dr. Eva-Maria Collins for reviewing this article.

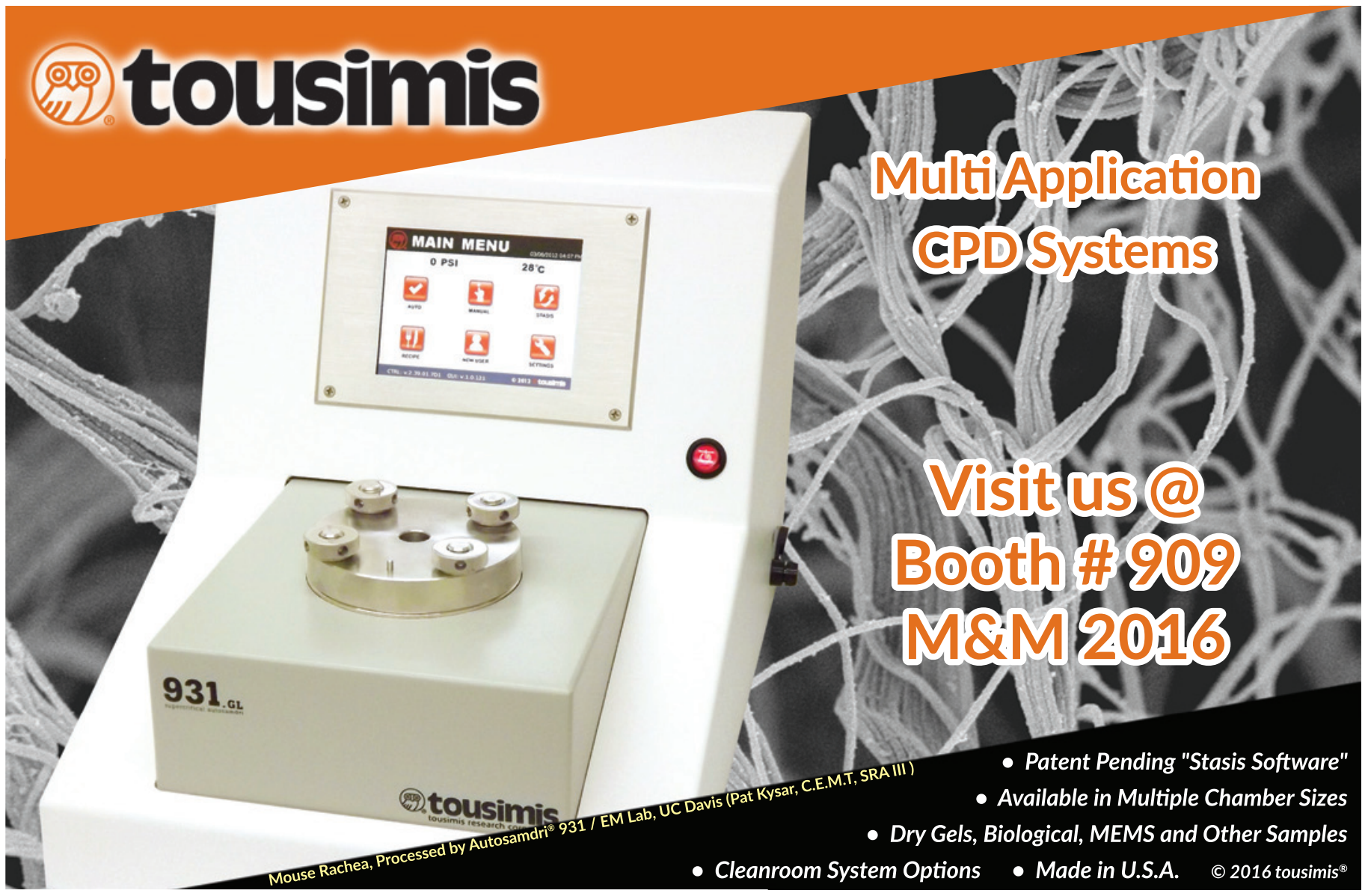




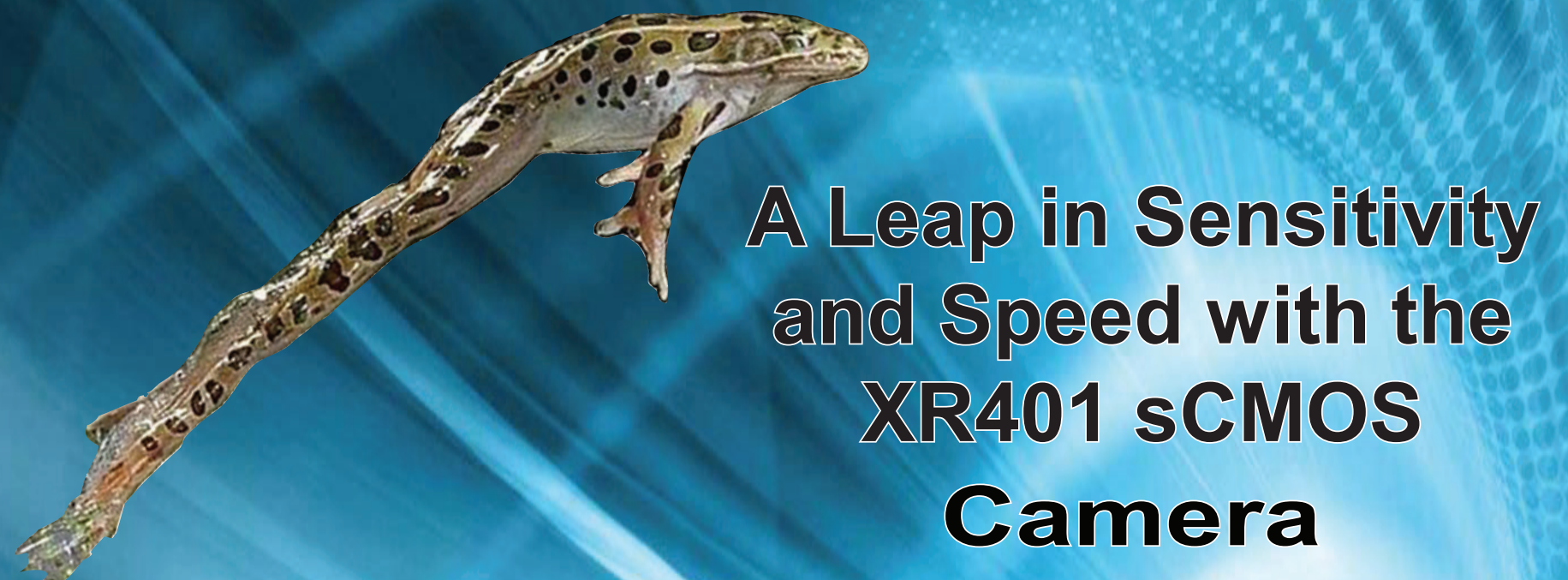

- Cryo TEM

- Low Dose TEM

- Diffraction

- In-Situ TEM

- Extraordinary speed

- Non-Blooming Sensor $0<2$ e/pixel noise

Adenovirus

Dr. Cameron Ackerley

The Hospital for Sick Children

\section{A Leap in Sensitivity and Speed with the XR401 sCMOS Camera}
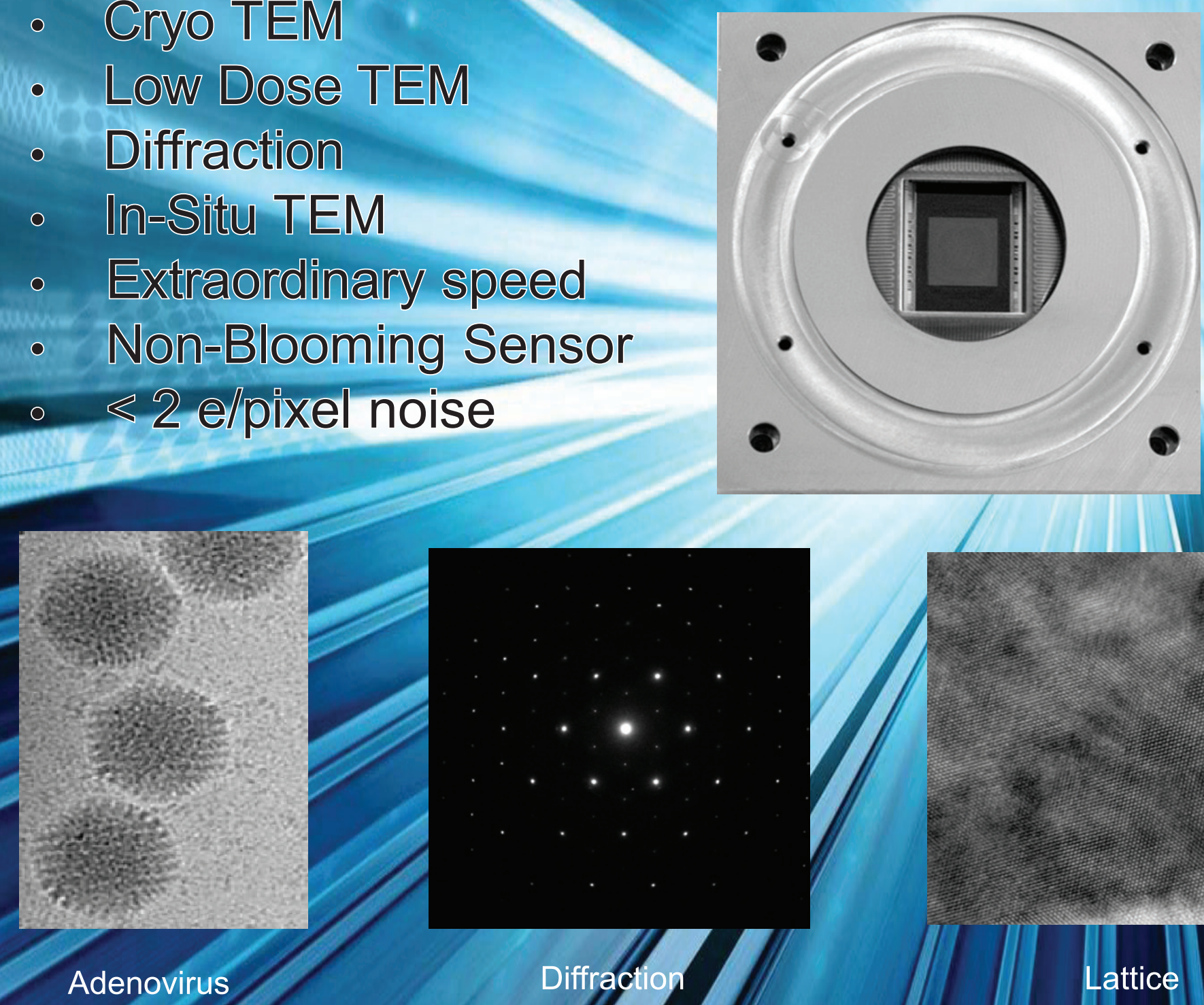

Dr. Pengfei Hu at the Shanghai University

Lattice 